Perspective

\title{
Adolescent Health - RKSK Perspective
}

\author{
Neha Awasthi', Amita Kashyap ${ }^{2}$
}

${ }^{1}$ Ph.D. Scholar, IIHMR University, Jaipur, Rajasthan, India.

${ }^{2}$ Prof. and HOD, Dept. of Social Medicine and Community Health, SMS Medical College, Jaipur, Rajasthan, India.

DOI: https://doi.org/10.24321/2349.2880.202005

\section{I $\quad \begin{array}{lllll}\mathbf{N} & \mathbf{F} & \mathbf{O}\end{array}$}

\section{Corresponding Author:}

Neha Awasthi, IIHMR University, Jaipur,

Rajasthan, India.

E-mail Id:

awa.neha@gmail.com

Orcid Id:

https://orcid.org/0000-0002-5930-9147

How to cite this article:

Awasthi N, Kashyap A. Adolescent Health - RKSK Perspective. Ind J Youth Adol Health 2020; 7(1): 27-31.

Date of Submission: 2020-08-07

Date of Acceptance: 2020-09-01

\section{$\begin{array}{llllllllllllll}\mathbf{A} & \mathbf{B} & \mathbf{S} & \mathbf{T} & \mathbf{R} & \mathbf{A} & \mathbf{C} & \mathbf{T}\end{array}$}

"Adolescence is like having only enough light to see the step directly

Sarah Addison Allen

\section{Global Perspective}

WHO defines, adolescents as young people between the ages of 10 and 19 years. More than 1.2 billion people worldwide are adolescent; this indicates that roughly one in every six people is an adolescent. ${ }^{1}$ Adolescents are usually considered as healthy group of people. But, a few facts break this myth: estimated 1.2 million adolescents died in 2015; over 3000 every day, mostly from preventable or treatable causes. $^{2}$ This period of transition between childhood to adulthood, ${ }^{3}$ is period of active growth and development: physical, sexual, social and emotional. ${ }^{4}$ Due to physical and hormonal changes adolescents struggle through image consciousness, identity crisis, attraction towards opposite sex, and control behavior of their gatekeepers. An attempt to prove themselves in the family and society and takes great toll on behavioral aspects of the adolescents and makes them vulnerable.

There is empirical evidence to prove that more than $33 \%$ of the disease burden and almost $60 \%$ of premature deaths among adults can be related to behaviour or conditions that triggered during adolescence. ${ }^{5}$ Adolescence is the last chance to correct whatever wrong habits inculcated in childhood for future healthy lifestyle. Hence, focusing on prevention of major risk factors for eliminating or reducing the chance of non-communicable diseases in adult life is the main thrust area for adolescent health. The major risks usually associated with adolescent health are injuries/ accidents, violence, depression, anxiety, suicidal tendency, RTI/STI, HIV/AIDS, early pregnancy, childbirth, abortions, substance abuse, nutrition, micronutrient deficiencies, under nutrition, obesity and lack of physical activity. ${ }^{6,7}$

Unintentional injuries are the leading cause of death in adolescents. In 2016, globally, road accidents took a toll of over 1, 35,000 adolescents. Depression is one of the leading causes of illness and disability among adolescents, and suicide is the second leading cause of death in adolescents. Interpersonal violence causes nearly a third of all adolescent male deaths in low- and middle-income countries of the WHO Region of the Americas. Globally, nearly one in three adolescent girls aged 15 to 19 
years ( 84 million) have been a victim of emotional, physical and/or sexual violence perpetrated by their husband or partner. An estimated 2.1 million adolescents were living with HIV in 2016. The leading cause of death for 15 to 19 year-old girls globally is complications from pregnancy and childbirth. Some $11 \%$ of all births worldwide are to girls aged 15 to 19 years. Many boys and girls in developing countries enter adolescence undernourished, making them more vulnerable to disease and early death. Paradoxically, globally, in 2016, over one in 6 adolescents aged 10 to 19 years was overweight. ${ }^{8}$

Globally, only 1 in 5 adolescents are estimated to do atleast 60 minutes of moderate-to-vigorous-intensity physical activity daily, which may include play, games, sports, but also activity for transportation (such as cycling and walking), or physical education. ${ }^{9}$ Worldwide, the prevalence of heavy episodic drinking among adolescents aged 15 to 19 years was $13.6 \%$ in 2016 , with males most at risk. ${ }^{10}$ The use of tobacco and cannabis are additional concerns. In 2016, based on data available from 130 countries, it was estimated that $5.6 \%$ of 15 to 16 year olds had used cannabis at least once in the preceding year. Many adult smokers have their first cigarette prior to the age of 18 years. ${ }^{11}$ Most research suggests that early (12-14 years old) to late (15-17 years old) adolescence is a critical risk period for the initiation of substance use and that substance use may peak among young people aged 18 to 25 years. ${ }^{12}$

Each phase of life since inception in mother's womb to old age needs tailored care and support. Adolescence is no exception, when new responses are required to support brain maturation, intense social engagement, and emotional control. ${ }^{13}$ Investment in adolescent health is expected to bring exponential growth and development especially when the Nation is having majority of young population. Improved adolescent health brings economic and larger societal benefits. This occurs through greater productivity, reduced health costs and enhanced social capital. ${ }^{14}$

\section{National Reality: India}

The highest number of adolescents in the world resides in India. ${ }^{15,16}$ Almost, one fifth (21.2\%) of the population is adolescent amounting to 243 million. ${ }^{17}$ According to UNFPA projections; India will continue to have the youngest populations in the world till $2030 .{ }^{18}$ The larger the proportion of adolescents in a country; the larger are the benefits and threats associated with them.

In India, pregnancy amongst teenage girls (9-15 years) is 7.9 percent (NFHS IV). "The unmet need for contraception in the age group 15 to 19 is 27 percent, which is the highest across all age groups. The top three causes of unintentional injury deaths in India are traffic accidents by falls and drowning. According to Global Burden of Disease, 2004,
Road Traffic Accidents (RTA) are responsible for 3.35 lakhs deaths in India in the 15 to 29 age group, making RTA a leading cause of death in this age group. Adolescents in India suffer from both under- and over-nutrition issues. In the age group 15-19, nearly half the girls (47 percent) and nearly three fifths of the boys (58 percent) are thin. At the same time, 2.4 percent of the girls and 1.7 percent of the boys in this age group are overweight. Nearly 2 per 1,000 adolescent girls and 1 per 1,000 adolescent boys aged 1519 suffer from diabetes. Findings from NFHS-3 show that 11 percent of young men and 1 percent of young women in age group of 15-19 had consumed alcohol. Almost 29 percent of the boys and 4 percent of the girls (15-19 years) use some kind of tobacco and more than 12 percent of the boys in this age group smoke cigarettes or bidi's."19

In order to, build a strong Nation today and stronger tomorrow, proper channelization of the abundant energies of adolescents into right direction is a necessity. At the national level, there are a number of policies that address the health and development needs of young people. Notable among the national policies addressing young people's health needs, Rashtriya Kishore Swasthya Karyakram (RKSK), 2014 is one of them, others are: National Population Policy (NPP) 2000, National AIDS Prevention and Control Policy 2002, National Youth Policy 2003, and National Youth Policy 2014. ${ }^{20}$

RKSK program was launched by Ministry of Health and Family Welfare in the year 2014. This program envisions, "all adolescents in India are able to realize their full potential by making informed and responsible decisions related to their health and well-being and by accessing the services and support they need to do so."21 The program strategized to meet the need of adolescent health in holistic manner addressing six thrust areas Reproductive and Sexual health (SRH) (improve knowledge, attitudes and behavior in relation to $\mathrm{SRH}$, reduce teenage pregnancies, prevent RTI/ STI, HIV/AIDS), Nutrition (under or over nutrition) , Mental health (acknowledging depression among adolescents, removing taboo associated and timely addressing the issue, preventing suicides), substance abuse , injuries, aggression and violence and Non-communicable diseases.

The highlights of this program are, medical advice and counseling to adolescents through Adolescent Friendly Health Clinic (in Rajasthan state it is known as UJALA Clinic) by doctor and designated counselors, peer counseling through trained peer counselors, quarterly adolescent health day at anganwadi centers, weekly iron folic acid supplementation, bi-annual de-worming and upkeep of menstrual hygiene.

\section{Way forward}

Holistic development of adolescent can be ensured by 
holistic efforts by all gatekeepers, sitting at healthcare facility is not enough. Gatekeepers such as family members, teachers, community (leaders, influencers and neighbors), healthcare service providers, NGOs etc. whose attitude and approach to adolescent play key pivotal role in growth of adolescents, should be addressed through behavior change communication for opening up acquiring more knowledge and skills for facilitating holistic development of adolescents. Adolescents in special conditions (differently-abled, street children, prisoners, orphans etc.) require special attention.

Though, parenting is a fulltime, demanding and breakless job yet we do not have to qualify to do it as doctors or engineers or for any other professional job. The first influence on any child is of parents. If this is restricting rather than expanding, this becomes hazardous for adolescents. That is why role of other family members, teachers, healthcare service providers, community members, NGO members and other gate keepers become crucial.

The first stepping stone to reaching out to adolescents is introspection by each gatekeeper. Are we able to understand the change in emotional, physical and mental needs of this phase of life? Are we able to understand change in time, and generation gap, the gap even more widened by advanced technology? If answer of any of the question is 'No' than we as a society should hold back, and unlearn what no longer is consistent with need of the hour, and learn how and what needs to be delivered in the best interest of the adolescents. In order to raise adolescents so as to make them competent to exercise their full potential and become productive and sensible citizen of India, all the gatekeepers has to have a right perspective themselves.

Acceptance for the changes in line with the needs of adolescents, will bring get gatekeepers closer to the goal of a healthy Nation. Acceptance sets the mind free from preconceived notions, judgments and prejudices, which in turn will help improve, relationship between gatekeepers and adolescence through mutual confidence, feeling of trust and independence with responsibilities.

In order to support an adolescent, firstly parents, family members, teachers, community members must be sensitive enough to understand the changing phase of child's life and change in environment from their generation to next generation. Knowing and acknowledging adolescents rights is another issue of concern in country like India, where, family and community set ups are usually very interfering or encroaching in each other's life, especially in the life of dependent ones.

Accepting the fact that adolescents are aggressive, assertive, daring, curious, experimental, emotional, energetic and experiencing sexual stimuli for the first time. Hence, their interest in sexual activity is natural, therefore it is necessary that adolescents get right information, in right environment by right people. Adequate and appropriate sex education by parents or teachers will satisfy adolescents outgrowing interest in subject and will restrict them from hazardous experiments. Health service providers especially doctors shall create such opportunity where they can have an open discussion with adolescents, their parents and other influential community member so as to break the ice over 'shy-away' topics like menstrual hygiene, sex and sexuality, RTI/STI, contraceptive needs, early marriages, societal pressure of early pregnancy, and safe abortions in community, in most scientific non-threatening way.

Medical Officer should organize community meetings to sensitize community members specially teachers, ASHAs and ANMS towards adolescents' need and update their knowledge and help them improve their communication skills to address adolescents in specific needs.

Roots of solution of problem like gender discrimination and teen age pregnancies followed by early marriages lies within family and society. Encouragement of girl's education specifically in rural areas would give them equal opportunity to become self-reliant. Teachers' involvement in enrollment of girls and restrain drop out of adolescent girls may; if not stop, restrict the early marriages. Counseling of adolescent girls and boys regarding contraception by counselors, ANMs, ASHAs along with sufficient and timely supply of contraceptive provided by the Government will reduce the unmet needs and will protect adolescents from $\mathrm{RTI} / \mathrm{STI}, \mathrm{HIV} / \mathrm{AIDS}$, and unsafe abortions.

It is accountability of teachers and parents to make adolescent aware about their vulnerability towards possible harassments as teenager within family or in the outside world. Community has to create safe surroundings for adolescent. Parents and teachers should prepare adolescents to prevent such situation (teaching about good touch and bad touch), to deal with it (quick responses-pushing, shouting and biting) and developing the confidence to report it, if faced. It is a complicated process and must be dealt so carefully so as to not to make adolescent frightened, paranoid or timid in the process. Self-defense classes should be incorporated as part of extracurricular activity. Community level talks by influential community members such as Sarpanchs, ward members, school principle, police, and NGO members regarding legal punishments to offenders without judging the victim will help adolescent grow confidence in community and the system.

Respecting adolescent's choices without any doubt or shame is another important aspect to raise a matured and confident adolescent. If adolescents are included in decision making in the family, given responsibility of households tasks and involved in socializing with community they 
become emotionally strong, confident and more resilient. Parents, teachers and community members must make adolescents understand difference between right choices and wrong choices and their respective repercussions and allow them to make choices independently and responsibly.

New experiences in adolescents life are essential as part of growth. Therefore such opportunities should deliberately be created where adolescents get exposure to new experiences (driving, going out independently etc.) in safe environment with an ability to identify right experience for right age. "Parents and teachers need to be stable in expressing their values and standards and relatively consistent in expressing their values, attitudes, ideas, and viewpoints to provide their adolescents with a frame of reference to test out their own views, ideals, and beliefs by entering into verbal conflict with their parents. Understanding about the teenager often changes between wanting to agree and wanting to disagree."22

Parents if capable then by themselves or else through career counselors or through teachers must help adolescents to plan or at least make them start to think about their professional inclination for their future and in the best interest of the Nation. This will help to control and channelize the young energy into constructive way. Exposure to bigger vision in life will reduce the importance of trivial momentary pleasures.

Parents concern to save their children from distraction as they foresee are excessive outings with friends, sexual conversation, rash driving, etc., is acceptable. But importance of peer group for the adolescents cannot be overshadowed by this concern. Parents and teachers must encourage their adolescents to participate with their peers and not necessarily be competing with them all the time. The majority of normally developing adolescents do not join peer groups whose values, attitudes, and rules of behavior differ greatly from their parents. If parents' expression is not clear, then adolescents do not know what things are positive ways." 23 Parents and teachers must timely identify this identity crisis in an adolescent so as to protect them from mental health problems or getting in to substance misuse to deal with this crisis by themselves.

Recognizing importance of peers and learning by peers is helpful to adolescent to have an enriched social life. While allowing adolescents to get involved with their peers it must be taken care that parents are in loop. Adolescents are likely to seek solace in their peers if their new ideas are ignored/ mocked in family. Involvement of parents with adolescents' peers and their families is equally important. This friendly bond will create a net of safety saving adolescents from any harm.

Adolescent with special conditions are such as distinctive economic, physical and mental conditions. It includes street adolescent, adolescents in orphanages or in juvenile custody, and specially-abled child (physically or mentally). An adolescent is an adolescent irrespective of any special condition. But an adolescent in special condition may require special attention, excessive mental and emotional support than others.

Parents with specially-abled child must also recognize growing phase of their child, the process may slower or faster than other adolescents. Parents should be sensitized to get timely professional help timely. The role of social welfare department and NGOs is crucial, to provide support to those who does not have sufficient emotional, mental and financial support from parents and community like street children, orphans or in juvenile custody. These children with no or less protection are more exposed to substance abuse, unprotected and/or forced sexual activity, poor mental health, poor sexual or reproductive health.

Adolescents in juvenile custody are the adolescent who knowingly or unknowingly have lost their path in life and might have lost their faith in society and the system. Bringing them to streamline and rehabilitating them in the society is a critical task so as to prevent them to become bigger threat to society and the Nation. Bringing the purpose in their life would need focused attention. NGO must find there focused area of work and help Nation by supporting these adolescents.

\section{Concluding Remarks}

Over the years, through the trainings of Medical officers, Counselors, ANMs and ASHAs, to address adolescents' health issues sensitively, society has gained a lot in opening up for adolescents need and handling them with care. Disparity among adolescents such as regional (rural/urban/ tribal/hilly), economical (rich/poor), educational (illiterate/ literate/educated), residential (orphanage, street children, slum dweller, juvenile custody, bad or good localities), social class (lower/middle/upper) and others cannot be just confined in a program/s or scheme/s. No matter how widened is the scope of the program or scheme. Equal opportunities and equal development of all the adolescents is essence of elimination of many adolescent-health-related social and health issues.

That is why, role of gatekeepers, to supervise and attend the area specific and adolescent specific needs, is indispensible. Thus, executors of such programs must pay special attention to area specific needs, and incorporate them in program while involving all the gate keepers. Joining hands by all the enabled gatekeepers together will create a safe circle for 'blossoming future' of the country.

Conflict of Interest: None 


\section{References}

1. https://www.copenhagenconsensus.com/publication/ rajasthan-priorities-adolescents-iihmr online file accessed on 04.12.18.

2. http://www.who.int/en/news-room/fact-sheets/detail/ adolescents-health-risks-and-solutions.

3. Merriam-Webster online dictionary; https://www. merriam-webster.com/dictionary/adolescence; accessed on Jan. 1, 2019.

4. Harry Medovy (2013); Problems of Adolescence; Can Med Assoc J 1964; 90(24): 1354-1360; PMCID: PMC 1927199

5. http://nhm.gov.in/nrhmcomponnets/reproductivechild-health/adolescent-health.html.

6. https://www.who.int/en/news-room/fact-sheets/ detail/adolescents-health-risks-and-solutions.

7. http://nhm.gov.in/images/pdf/programmes/rkskstrategy-handbook.pdf.

8. https://www.who.int/en/news-room/fact-sheets/ detail/adolescents-health-risks-and-solutions.

9. https://www.who.int/en/news-room/fact-sheets/ detail/adolescents-health-risks-and-solutions.

10. https://www.who.int/news-room/fact-sheets/detail/ adolescent-mental-health.

11. http://www.who.int/news-room/fact-sheets/detail/ adolescent-mental-health.

12. https://www.unodc.org/wdr2018/prelaunch/WDR18 Booklet_1_EXSUM.pdf.

13. https://www.thelancet.com/journals/lancet/article/ PIIS0140-6736(17)32417-0/fulltext.

14. https://www.who.int/maternal_child_adolescent/ topics/adolescence/why-invest/en/.

15. https://india.unfpa.org/en/topics/young-people-12 online file accessed on.

16. The State of the World's Children 2011 , UNICEF, https:// www.unicef.org/sowc2011/statistics.php.

17. http://nhm.gov.in/images/pdf/programmes/RKSK/ RKSK_Strategy_Handbook.pdf pg. no. 25.

18. https://india.unfpa.org/en/topics/young-people-12 online file accessed on.

19. http://www.nhm.gov.in/images/pdf/programmes/ RKSK/RKSK_Strategy_Handbook.pdf.

20. http://www.nhm.gov.in/images/pdf/programmes/ RKSK/RKSK_Strategy_Handbook.pdf.

21. http://www.nhm.gov.in/images/pdf/programmes/ RKSK/RKSK_Strategy_Handbook.pdf.

22. (PDF) Role of parents, Teachers, and Community in Adolescents' issues. Available from: https://www. researchgate.net/publication/308892358_Role_of_ parents_Teachers_and_Community_in_Adolescents_ issues [accessed Jan 08 2019].

23. (PDF) Role of parents, Teachers, and Community in Adolescents` issues. Available from: https://www.
researchgate.net/publication/308892358_Role_of_ parents_Teachers_and_Community_in_Adolescents_ issues [accessed Jan 08 2019]. 